\title{
Article
}

\section{The Speed of Ingestion of a Sugary Beverage Has an Effect on the Acute Metabolic Response to Fructose}

\author{
Mehmet Kanbay ${ }^{1, *(D)}$, Begum Guler ${ }^{2}$ (D) Lale A. Ertuglu ${ }^{2} \mathbb{D}$, Tuncay Dagel ${ }^{1}$, Baris Afsar ${ }^{3}$, Said Incir ${ }^{4}$, \\ Arzu Baygul ${ }^{5}$, Adrian Covic ${ }^{6}$, Ana Andres-Hernando ${ }^{7}$, Laura Gabriela Sánchez-Lozada ${ }^{8}$ (D), Miguel A. Lanaspa ${ }^{7}$ \\ and Richard J. Johnson ${ }^{7}$
}

Citation: Kanbay, M.; Guler, B.; Ertuglu, L.A.; Dagel, T.; Afsar, B.; Incir, S.; Baygul, A.; Covic, A.; Andres-Hernando, A.;

Sánchez-Lozada, L.G.; et al. The Speed of Ingestion of a Sugary Beverage Has an Effect on the Acute Metabolic Response to Fructose. Nutrients 2021, 13, 1916. https:// doi.org/10.3390/nu13061916

Academic Editors: Emily Sonestedt and Rosa Casas

Received: 9 March 2021

Accepted: 29 April 2021

Published: 2 June 2021

Publisher's Note: MDPI stays neutral with regard to jurisdictional claims in published maps and institutional affiliations.

Copyright: (c) 2021 by the authors Licensee MDPI, Basel, Switzerland. This article is an open access article distributed under the terms and conditions of the Creative Commons Attribution (CC BY) license (https:// creativecommons.org/licenses/by/ $4.0 /)$.
1 Division of Nephrology, Department of Medicine, Koc University School of Medicine, Istanbul 34010, Turkey; tdagel@kuh.ku.edu.tr

2 Department of Medicine, Koc University School of Medicine, Istanbul 34450, Turkey; bguler@kuh.ku.edu.tr (B.G.); lertuglu14@ku.edu.tr (L.A.E.)

3 Division of Nephrology, Department of Internal Medicine, Suleyman Demirel University School of Medicine, Isparta 32260, Turkey; afsarbrs@yahoo.com

4 Department of Biochemistry, Koc University School of Medicine, Istanbul 34010, Turkey; sincir@kuh.ku.edu.tr

5 Department of Bioistastics, Koc University School of Medicine, Istanbul 34010, Turkey; abaygul@ku.edu.tr

6 Department of Nephrology, Grigore T. Popa' University of Medicine, 700115 Iasi, Romania; accovic@gmail.com

7 Division of Renal Diseases and Hypertension, University of Colorado Denver, Aurora, CO 80045, USA; ana.andreshernando@cuanschutz.edu (A.A.-H.); miguel.lanaspagarcia@cuanschutz.edu (M.A.L.); richard.johnson@cuanschutz.edu (R.J.J.)

8 Department of Cardio-Renal Physiopathology, Instituto Nacional de Cardiología-Ignacio Chavez, Mexico City, Mexico; lgsanchezlozada@gmail.com

* Correspondence: mkanbay@ku.edu.tr or drkanbay@yahoo.com; Tel.: +90-21-2250-8250

Abstract: Background: The consumption of sweetened beverages is associated with increased risk of metabolic syndrome, cardiovascular disease, and type 2 diabetes mellitus. Objective: We hypothesized that the metabolic effects of fructose in sugary beverages might be modulated by the speed of ingestion in addition to the overall amount. Design: Thirty healthy subjects free of any disease and medication were recruited into two groups. After overnight fasting, subjects in group 1 drank $500 \mathrm{~mL}$ of apple juice over an hour by drinking $125 \mathrm{~mL}$ every $15 \mathrm{~min}$, while subjects in group 2 drank $500 \mathrm{~mL}$ of apple juice over $5 \mathrm{~min}$. Blood samples were collected at time zero and 15, 30,60 , and $120 \mathrm{~min}$ after ingestion to be analyzed for serum glucose, insulin, homeostatic model assessment (HOMA-IR) score, fibroblast growth factor 21, copeptin, osmolarity, sodium, blood urea nitrogen (BUN), lactate, uric acid, and phosphate levels. Results: Serum glucose, insulin, HOMAIR, fibroblast growth factor 21, copeptin, osmolarity, sodium, BUN, and lactate levels increased following apple juice ingestion. The increases were greater in the fast-drinking group, which were more significant after $15 \mathrm{~min}$ and $30 \mathrm{~min}$ compared to baseline. The changes in uric acid were not statistically different between the groups. Phosphate levels significantly increased only in the fast-drinking group. Conclusion: Fast ingestion of $100 \%$ apple juice causes a significantly greater metabolic response, which may be associated with negative long-term outcomes. Our findings suggest that the rate of ingestion must be considered when evaluating the metabolic impacts of sweetened beverage consumption.

Keywords: sugary beverage; fibroblast growth factor 21; osmolarity; copeptin

\section{Introduction}

As much as $20 \%$ of daily total energy intake is through caloric beverages, according to the United States Department of Agriculture (USDA) [1]. Among youth, soft drinks and $100 \%$ fruit juice, which have high sugar and caloric contents, account for more than one-fifth of total beverage intake [1]. However, mounting evidence indicates that heavy 
consumption of soft drinks contributes to the development of obesity, increased risk of cardiovascular disease (CVD), and type 2 diabetes mellitus (T2DM) [2,3]. Notably, the European Prospective Investigation into Cancer and Nutrition (EPIC) cohort reported a positive association between consumption of soft drinks and all-cause mortality [4].

Fructose is the main sugar found in both $100 \%$ fruit juice and sugar-sweetened beverages [5] and is responsible of many of the health consequences associated with sweetened beverages, including insulin resistance, dyslipidemia, and visceral obesity [6]. Fructose can vary in percentage from $50 \%$ to $65 \%$ of sugar content in sugar-sweetened beverages and up to $67 \%$ in some $100 \%$ fruit juices, which is up to 10 times more than that present in a whole fruit. Contrary to common belief, the fructose contents of $100 \%$ fruit juices are equal to or even higher than most sugar-sweetened beverages, reaching concentrations of $67 \mathrm{~g} / \mathrm{L}$ in some commercially available $100 \%$ apple juices [5]. Although $100 \%$ fruit juice is usually perceived as a healthy beverage and a rich supply of vitamins and phytonutrients, it is not the same as whole fruit since fiber content is lost while sugar content is considerably higher.

Although fructose and glucose have the same chemical formula, fructose metabolism is independent of insulin and does not have hormonal regulation. Fructose generates more pyruvate and induces gluconeogenesis, glycogen accumulation, and lipogenesis. Recent studies suggest that, after ingestion in low doses, fructose is primarily metabolized in the small intestines, while high doses saturate the absorption of fructose in the intestine, which causes higher amounts of fructose to be carried and metabolized in the liver [7], thereby triggering hepatic lipid accumulation $[7,8]$. The total increased fatty acid formation may contribute to weight gain [9], while intrahepatic lipid accumulation and fructose-dependent oxidative stress are believed to induce nonalcoholic steatohepatitis $[8,10]$. A high fructose intake has been consistently linked to metabolic syndrome both in humans [11] and in animal models [12,13].

One aspect of sugary beverages is that they are not only high in fructose content, but also typically ingested rapidly. Studies have shown that the mechanism via which fructose induces metabolic syndrome is not dependent on the caloric content of fructose, but rather due to the unique ability of fructose to cause intracellular adenosine triphosphate (ATP) depletion and activate an adenine nucleotide degradation pathway in the liver $[8,14-16]$. The effect of inducing ATP depletion is more severe with a higher concentration of fructose [8]. This raises the possibility that the speed of ingestion might be an important risk factor for developing metabolic effects of fructose. Indeed, there is some evidence that sugary beverages carry a greater risk for metabolic syndrome than when sugar is in the food $[17,18]$.

If the speed of ingestion (which would translate into differences in delivery time to the liver) is important in how fructose causes metabolic effects, then the ideal study to test the hypothesis would be to give a fructose-containing solution at two different rates to volunteers. We, therefore, performed a study in which apple juice (rich in fructose) was administered over $5 \mathrm{~min}$ versus over $1 \mathrm{~h}$ to healthy adult volunteers. We compared the metabolic effects of fast and slow fructose consumption by evaluating changes in serum glucose, insulin, homeostatic model assessment (HOMA-IR) score, copeptin, sodium, blood urea nitrogen (BUN), osmolarity, fibroblast growth factor 21 (FGF-21), uric acid, lactate, and phosphate concentrations after fructose ingestion. Serum copeptin is a stable biomarker of vasopressin (AVP) and predicts incident obesity, type II diabetes mellitus (DM) $[19,20]$, and kidney and CVD [21]. In addition, recent studies showed that fructose ingestion increases serum copeptin in both animals and humans [22-24], and that blocking the vasopressin $1 \mathrm{~b}$ receptor can block the metabolic effects of fructose [24]. FGF-21 is a key regulatory hormone in glucose and lipid metabolism which was shown to enhance hepatic fatty acid oxidation and ketogenesis in both animals and humans, whereas serum uric acid is a critical factor in the pathogenesis of fructose-induced metabolic syndrome and a strong predictor of clinical outcome [25]. We hypothesized that slow consumption of soft drinks would cause less change in serum copeptin, sodium, BUN, osmolarity, FGF-21, lactic acid, 
uric acid, and phosphate compared to fast consumption, which may be helpful to alleviate the metabolic effects of excess soft-drink consumption.

\section{Materials and Methods}

\subsection{Characteristics of the Study Population}

Thirty healthy, nonobese participants without any systemic disease and receiving no medications and alcohol were included to this study. All volunteers underwent the intervention at 8:00 a.m. after overnight fasting. Participants did not eat or drink except water for $8 \mathrm{~h}$ before the intervention.

Baseline laboratory tests were performed before starting to drink apple juice. Baseline measurements included serum glucose, insulin, HOMA-IR score, FGF-21, copeptin, osmolarity, sodium, BUN, lactic acid, uric acid, and phosphate, as well as complete blood count, liver, and kidney function tests. The study protocol is summarized in Figure 1.

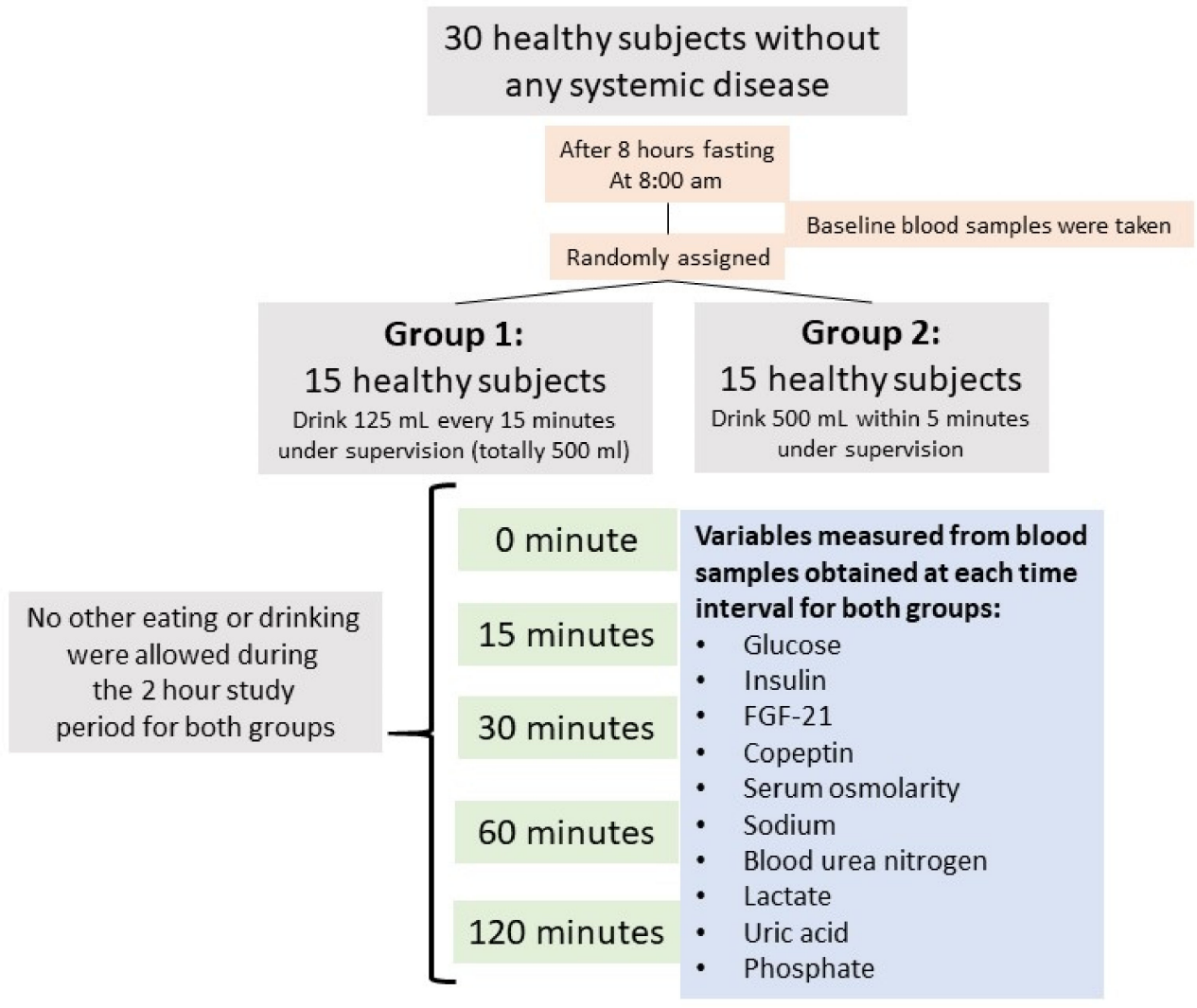

Figure 1. Flow diagram of the study design.

The Koc University School of Medicine ethics committee approved the study protocol. Written informed consent was taken from all participants before enrollment.

\subsection{Study Protocol}

Each subject was given a total of $500 \mathrm{~mL}$ of $100 \%$ pure, commercially available apple juice to consume during the intervention (https:/ / www.isrctn.com/ISRCTN14798840). The participants were randomly allocated to either group 1 or group 2 . We used 100\% apple juice as the fructose source since it has a higher fructose-to-glucose ratio and has no antioxidant effect [5]. Each participant drank the same apple juice. The participants in group 1 were instructed to drink $125 \mathrm{~mL}$ every $15 \mathrm{~min}$ under direct supervision four times until a total of $500 \mathrm{~mL}$ was consumed. The participants in group 2 were instructed to drink $500 \mathrm{~mL}$ of apple juice within $5 \mathrm{~min}$ under direct supervision. No other eating or drinking was allowed during the $2 \mathrm{~h}$ study period for both groups. The subjects did not perform any physical activity during the study period. 


\subsection{Serum Measurements}

Blood samples were collected for laboratory analysis at baseline and 15, 30, 60, and 120 min after apple juice consumption initiation. For the biochemical analysis, participants' blood samples were collected into dry tubes and centrifuged promptly $(3500 \times g)$ for $10 \mathrm{~min}$ at $4{ }^{\circ} \mathrm{C}$. Sera were separated in aliquots and were frozen rapidly at $-80^{\circ} \mathrm{C}$ for the copeptin and FGF-21 measurements. The detections of glucose, insulin, sodium, BUN, lactic acid, uric acid, and phosphate were performed immediately using a Roche Cobas 6000 analyzer (Roche, Mannheim, Germany). Serum osmolarity was evaluated using the freezing-point Osmometer K-7400S (Knauer, Berlin, Germany), which permits freezing-point depression to be assessed. Copeptin and FGF-21 measurements in serum were determined by sandwich enzyme-linked immunosorbent assay (ELISA) using commercial kits (Cloud-Clone Corp., Wuhan, China). Intra- and inter-coefficients of variabilities were $<10 \%$ and $<12 \%$ for both copeptin and FGF-21 levels. Insulin resistance was estimated according to the HOMA-IR. For calculations, the following formula was used: HOMA-IR $=$ (plasma glucose $\times$ plasma insulin/405), where glucose is in mass units ( $\mathrm{mg} / \mathrm{dL})$ [26].

\subsection{Statistical Analysis}

Continuous variables were presented as the mean \pm standard deviation (SD), while categorical variables were presented as the frequency (\%). Repeated-measures ANOVA was used to examine the difference of variables through time points, as well as the relationship between the time effect and group membership. Continuous variables were examined for normality using the Shapiro-Wilk test. The Mann-Whitney U test and Kruskal-Wallis test were performed to compare two independent continuous variables not normally distributed. All statistics were analyzed using SPSS IBM Corp. Released 2019. IBM SPSS Statistics for Windows, Version 26.0. Armonk, NY: IBM Corp. A $p$-value $<0.05$ was considered statistically significant.

\section{Results}

\subsection{Characteristics of the Study Population}

A total of 30 subjects ( 13 men and 17 women) participated in the study. Table 1 presents the detailed demographic and clinical data of participants enrolled. The mean age of the subjects was $26.1 \pm 3.7$ years. All baseline characteristics were similar between the two groups, including blood pressure, body mass index, tobacco use, and laboratory values.

The baseline plasma glucose, insulin, HOMA-IR score, FGF-21, osmolarity, copeptin, sodium, BUN, uric acid, lactate, and phosphate levels were not statistically different between the groups. Changes in all parameters were significantly different between group 1 and group 2 with the exception of uric acid levels (Table 2).

\subsection{Effect of Intervention on Serum Glucose, Insulin, and HOMA-IR}

In terms of magnitude, the increase in serum glucose was higher and steeper with fast ingestion of the apple juice when compared to that after slow ingestion (Figure 2). In group 2, glucose levels reached a peak after $30 \mathrm{~min}$ and declined afterward, while glucose levels demonstrated a subtle incline until $60 \mathrm{~min}$ without a dramatic peak level in group 1 (Figure 2A). The increases in serum glucose levels from baseline to $15 \mathrm{~min}$ and $30 \mathrm{~min}$ were significantly higher in group 2 ( $p=0.001$ for both) (Table 3 ), while the changes in serum glucose levels after $60 \mathrm{~min}$ and $120 \mathrm{~min}$ were not statistically different between the two groups. 
Table 1. Baseline characteristics of the study population.

\begin{tabular}{|c|c|c|c|c|}
\hline \multirow{2}{*}{ Characteristics } & \multicolumn{4}{|c|}{30 Healthy Subjects } \\
\hline & Overall & Group 1 & Group 2 & $p$ \\
\hline Number & 30 & 15 & 15 & \\
\hline Age, years $($ mean $\pm S D)$ & $26.1 \pm 3.7$ & $25.33 \pm 1.8$ & $26.9 \pm 4.9$ & 0.7 \\
\hline Gender (male) n (\%) & $13(43.3 \%)$ & $6(40 \%)$ & $7(46.7 \%)$ & 0.9 \\
\hline Smoking, $\mathrm{n}(\%)$ & $4(13.3 \%)$ & $2(13.3 \%)$ & $2(13.3 \%)$ & 0.9 \\
\hline BMI, $\mathrm{kg} / \mathrm{m}^{2}$ (median $\left.\pm \mathrm{IQR}\right)$ & $22.9 \pm 4.1$ & $22.86 \pm 6.3$ & $22.9 \pm 2.1$ & 0.8 \\
\hline Systolic BP $(\mathrm{mmHg})$ & $109.2(105.9 \pm 113.3)$ & $108.5(104.8 \pm 112.2)$ & $109.5(105.8 \pm 113.2)$ & 0.9 \\
\hline Diastolic BP (mmHg) & $74.2(70.9 \pm 76.3)$ & $74.5(70.8 \pm 76.8)$ & $73.9(70.9 \pm 75.9)$ & 0.9 \\
\hline Hemoglobin (median $\pm \mathrm{IQR}$ ) & $14.4 \pm 3.1$ & $14.1 \pm 2.5$ & $14.6 \pm 3.1$ & 0.5 \\
\hline ALT-U/L (median \pm IQR) & $12.9 \pm 11.7$ & $11 \pm 9.2$ & $14.3 \pm 22.7$ & 0.1 \\
\hline GGT-U/L (median \pm IQR) & $12 \pm 10$ & $12 \pm 8$ & $12 \pm 13$ & 0.8 \\
\hline Creatinine-mg/dL (median \pm IQR) & $0.7 \pm 0.3$ & $0.7 \pm 0.2$ & $0.8 \pm 0.3$ & 0.5 \\
\hline
\end{tabular}

$p<0.05$ is significant. BMI—body mass index, BP—blood pressure, IQR—interquartile range, ALT—alanine aminotransferase, GGT—gamma-glutamyl transferase.

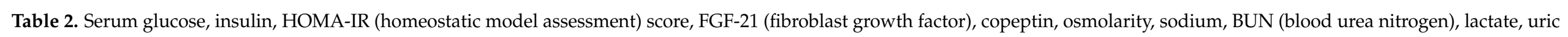
acid, and phosphate levels after the ingestion of $500 \mathrm{~mL}$ of apple juice over time.

\begin{tabular}{|c|c|c|c|c|c|c|c|}
\hline & Baseline & $15 \mathrm{~min}$ & $30 \mathrm{~min}$ & $60 \mathrm{~min}$ & $120 \mathrm{~min}$ & $p$-Value ${ }^{a}$ & $p$-Value ${ }^{b}$ \\
\hline \multicolumn{6}{|c|}{ Glucose (mg/dL) } & $<0.001$ & $<0.001$ \\
\hline Group 1 & $66.4 \pm 6.3$ & $76 \pm 18$ & $84.6 \pm 10$ & $86.1 \pm 1.5$ & $76.6 \pm 15.1$ & & \\
\hline Group 2 & $78 \pm 18.7$ & $102.5 \pm 17.3$ & $113.6 \pm 25$ & $85.3 \pm 30.2$ & $77.8 \pm 9.2$ & & \\
\hline \multicolumn{6}{|c|}{ Insulin $(\mu \mathrm{IU} / \mathrm{mL})$} & $<0.001$ & 0.001 \\
\hline Group 1 & $8.4 \pm 5.5$ & $15.8 \pm 10.5$ & $33.8 \pm 21.7$ & $48.3 \pm 35.8$ & $10.7 \pm 5.9$ & & \\
\hline Group 2 & $11.9 \pm 7.4$ & $35.7 \pm 19.4$ & $49 \pm 36.2$ & $24.7 \pm 24.4$ & $8.7 \pm 7.4$ & & \\
\hline \multicolumn{6}{|c|}{ HOMA-IR score } & $<0.001$ & $<0.001$ \\
\hline Group 1 & $1.7 \pm 1.0$ & $4.5 \pm 4.0$ & $7.9 \pm 3.9$ & $11 \pm 5.7$ & $3.1 \pm 4.4$ & & \\
\hline Group 2 & $2.0 \pm 1.0$ & $12.3 \pm 9.6$ & $15.4 \pm 10.9$ & $8.0 \pm 4.1$ & $3.3 \pm 2.2$ & & \\
\hline
\end{tabular}


Table 2. Cont

\begin{tabular}{|c|c|c|c|c|c|c|c|}
\hline & Baseline & $15 \mathrm{~min}$ & $30 \mathrm{~min}$ & $60 \mathrm{~min}$ & $120 \mathrm{~min}$ & $p$-Value ${ }^{\mathrm{a}}$ & $p$-Value ${ }^{b}$ \\
\hline \multicolumn{6}{|c|}{ FGF-21 (pg/mL) } & $<0.001$ & $<0.001$ \\
\hline Group 1 & $16.4 \pm 17.2$ & $20.5 \pm 13.7$ & $22.1 \pm 16.2$ & $24.5 \pm 15.6$ & $18.9 \pm 14.1$ & & \\
\hline Group 2 & $18.3 \pm 15.4$ & $31 \pm 12.7$ & $36.8 \pm 11.2$ & $43.9 \pm 17.1$ & $25.4 \pm 17.2$ & & \\
\hline \multicolumn{6}{|c|}{ Copeptin (pmol/L) } & $<0.001$ & 0.044 \\
\hline Group 1 & $45.6 \pm 52.9$ & $56.5 \pm 46.8$ & $60.1 \pm 52.4$ & $54.8 \pm 53$ & $47.9 \pm 35.9$ & & \\
\hline Group 2 & $58.5 \pm 61.8$ & $98.7 \pm 64.6$ & $99.2 \pm 57.6$ & $74.7 \pm 60.9$ & $60.4 \pm 30.2$ & & \\
\hline Group 1 & $283.7 \pm 5.6$ & $284.5 \pm 8.7$ & $283.9 \pm 6.5$ & $284.5 \pm 6.6$ & $284.9 \pm 7.9$ & & \\
\hline Group 2 & $284.7 \pm 5.4$ & $289.2 \pm 6.6$ & $291.8 \pm 4.9$ & $289.8 \pm 6.8$ & $286.2 \pm 5.3$ & & \\
\hline \multicolumn{6}{|c|}{ Sodium (mmol/L) } & $<0.001$ & $<0.001$ \\
\hline Group 1 & $137.6 \pm 1.8$ & $137.9 \pm 2.0$ & $138 \pm 1.6$ & $137.9 \pm 1.5$ & $138.2 \pm 1.7$ & & \\
\hline Group 2 & $138.1 \pm 1.2$ & $140.2 \pm 1.0$ & $141.9 \pm 0.8$ & $139.7 \pm 0.8$ & $138.5 \pm 1.2$ & & \\
\hline \multicolumn{6}{|c|}{ BUN (mg/dL) } & $<0.001$ & $<0.001$ \\
\hline Group 1 & $11.9 \pm \underline{4}$ & $11.7 \pm 4.0$ & $11.8 \pm 3.9$ & $11.3 \pm 3.6$ & $10.5 \pm 3.2$ & & \\
\hline \multicolumn{6}{|c|}{ Lactic acid (mmol/L) } & $<0.001$ & $<0.001$ \\
\hline Group 1 & $0.9 \pm 0.5$ & $1 \pm 0.4$ & $1.5 \pm 0.5$ & $1.9 \pm 0.7$ & $1.2 \pm 0.4$ & & \\
\hline Group 2 & $1 \pm 0.4$ & $1.8 \pm 0.4$ & $2.6 \pm 0.8$ & $2.5 \pm 0.8$ & $1.4 \pm 0.7$ & & \\
\hline \multicolumn{6}{|c|}{ Phosphate (mg/dL) } & 0.022 & $<0.001$ \\
\hline Group 1 & $3.4 \pm 0.8$ & $3.4 \pm 0.7$ & $3.5 \pm 0.6$ & $3.4 \pm 0.7$ & $3.5 \pm 0.8$ & & \\
\hline Group 2 & $3.5 \pm 0.4$ & $3.7 \pm 0.2$ & $3.9 \pm 0.3$ & $3.9 \pm 0.7$ & $3.8 \pm 0.7$ & & \\
\hline \multicolumn{6}{|c|}{ Uric acid (mg/dL) } & $<0.001$ & 0.48 \\
\hline Group 1 & $4.3 \pm 1.5$ & $4.3 \pm 1.4$ & $4.5 \pm 1.7$ & $4.6 \pm 1.7$ & $4.5 \pm 1.7$ & & \\
\hline Group 2 & $4.4 \pm 1.1$ & $4.6 \pm 1.1$ & $4.7 \pm 0.9$ & $4.8 \pm 1.1$ & $4.6 \pm 1.3$ & & \\
\hline
\end{tabular}

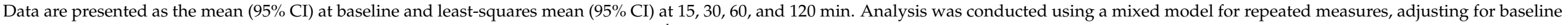

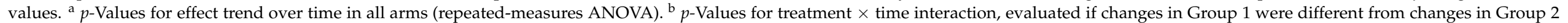

(repeated-measures ANOVA). 

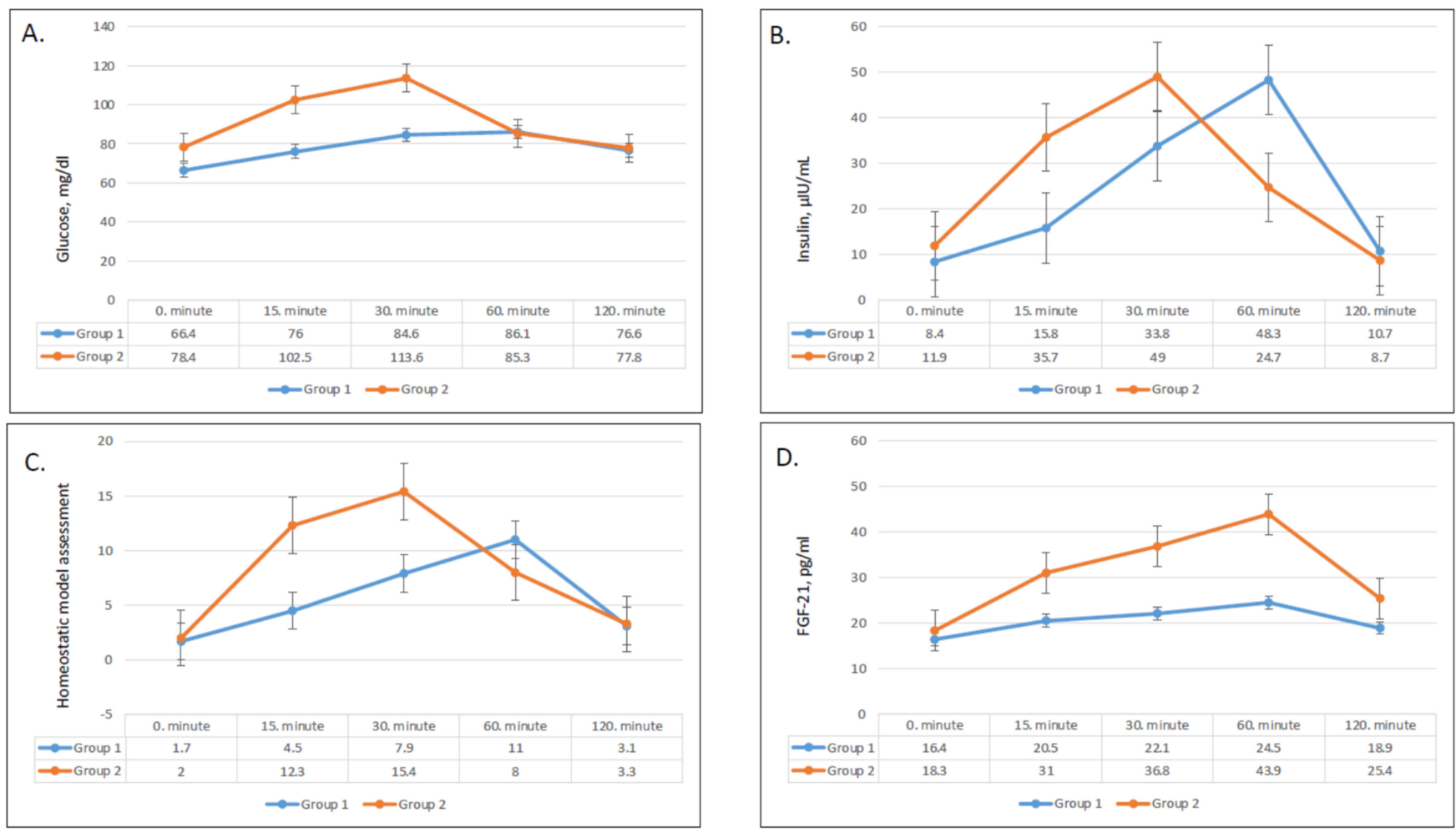

Figure 2. Changes in plasma glucose (A), plasma insulin (B), HOMA-IR (homeostatic model assessment) (C), and FGF-21 (fibroblast growth factor 21) (D) values in group 1 and group 2.

Serum insulin levels followed a similar trend to serum glucose levels (Figure 2B). Insulin levels showed a sharper and higher increase and an earlier drop after fast ingestion when compared with slow ingestion. Group 1 reached peak insulin levels after $60 \mathrm{~min}$, while group 2 reached peak levels after $30 \mathrm{~min}$. Compared with baseline, the increase in insulin levels was significantly greater in group 2 after $15 \mathrm{~min}, 30 \mathrm{~min}$, and $60 \mathrm{~min}$ ( $p=0.004,0.03$, and 0.02, respectively; Table 3). As compared with baseline levels, the difference in serum insulin levels remained significantly higher in group 2 until $60 \mathrm{~min}$ (Figure 2B).

The shifts in HOMA-IR levels paralleled serum insulin levels (Figure 2C) and increased following juice ingestion in both groups. The HOMA-IR levels of group 2 had a higher rise and quicker decline compared to group 1. The increases in HOMA-IR levels from baseline to $15 \mathrm{~min}$ and $30 \mathrm{~min}$ were significantly higher in group $2(p=0.003$ and 0.04 , respectively; Table 3), while the difference was insignificant after $60 \mathrm{~min}$ (Table 3).

\subsection{Effect on FGF-21}

The pattern of serum FGF-21 levels over time was greater and steeper rise after fast apple juice consumption compared to slow consumption. Serum FGF-21 steadily increased in both groups until reaching a peak after $60 \mathrm{~min}$ and decreased after $120 \mathrm{~min}$ (Figure 2D). The differences in FGF-21 concentrations compared with baseline were consistently higher in group 2 at all times $(p<0.01$ for all) (Table 3$)$. 
Table 3. The differences in glucose, insulin, HOMA-IR (homeostatic model assessment) score, FGF-21 (fibroblast growth factor), copeptin, osmolarity, sodium, BUN (blood urea nitrogen), lactate, uric acid, and phosphate levels compared with baseline after $500 \mathrm{~mL}$ of juice ingestion.

\begin{tabular}{|c|c|c|c|c|}
\hline & Baseline-15 min & Baseline-30 $\mathrm{min}$ & Baseline-60 min & Baseline-120 $\mathrm{min}$ \\
\hline \multicolumn{5}{|c|}{ Glucose (mg/dL) } \\
\hline Group 1 & $11.6 \pm 9.2$ & $20.5 \pm 7.9$ & $19.7 \pm 13.7$ & $8.3 \pm 112.7$ \\
\hline Group 2 & $31.7 \pm 14.7$ & $38.2 \pm 13.4$ & $13.6 \pm 15.7$ & $6.7 \pm 8.3$ \\
\hline$p$-Value & $<0.001$ & $<0.001$ & 0.213 & 0.983 \\
\hline \multicolumn{5}{|c|}{ Insulin $(\mu \mathrm{IU} / \mathrm{mL})$} \\
\hline Group 1 & $11.4 \pm 13.5$ & $22.9 \pm 12.8$ & $33.9 \pm 20.1$ & $6.1 \pm 20.2$ \\
\hline Group 2 & $35.8 \pm 31.3$ & $42.9 \pm 30.2$ & $18.6 \pm 15.4$ & $1.9 \pm 6.8$ \\
\hline$p$-Value & 0.004 & 0.033 & 0.019 & 0.494 \\
\hline \multicolumn{5}{|c|}{ HOMA-IR (Homeostatic model assessment) } \\
\hline Group 1 & $2.9 \pm 3.7$ & $6.2 \pm 3.6$ & $9.4 \pm 6.1$ & $1.5 \pm 4.6$ \\
\hline Group 2 & $10.3 \pm 9.8$ & $13.4 \pm 10.7$ & $6.0 \pm 4.2$ & $1.2 \pm 1.8$ \\
\hline$p$-Value & 0.003 & 0.040 & 0.078 & 0.494 \\
\hline \multicolumn{5}{|c|}{ FGF-21 (pg/mL) } \\
\hline Group 1 & $3.7 \pm 7.1$ & $6.6 \pm 7.5$ & $6.5 \pm 6.9$ & $-1.3 \pm 8.7$ \\
\hline Group 2 & $14.8 \pm 7.5$ & $21.9 \pm 7.4$ & $24.5 \pm 11.7$ & $8.9 \pm 8.4$ \\
\hline$p$-Value & $<0.001$ & $<0.001$ & $<0.001$ & 0.001 \\
\hline \multicolumn{5}{|c|}{ Copeptin (pmol/L) } \\
\hline Group 1 & $18.8 \pm 30.6$ & $23.3 \pm 36.4$ & $20.3 \pm 31.9$ & $2.6 \pm 10.6$ \\
\hline Group 2 & $35.2 \pm 24.1$ & $46.2 \pm 28$ & $20.2 \pm 24.2$ & $2.7 \pm 15.4$ \\
\hline$p$-Value & 0.005 & 0.001 & 0.576 & 0.604 \\
\hline \multicolumn{5}{|c|}{ Osmolarity (mOsm/L) } \\
\hline Group 1 & $0.5 \pm 2.5$ & $1.2 \pm 1.5$ & $1.3 \pm 1.3$ & $0.8 \pm 2$ \\
\hline Group 2 & $5.1 \pm 2.3$ & $6.4 \pm 2.1$ & $4.3 \pm 3.7$ & $1.5 \pm 2.3$ \\
\hline$p$-Value & $<0.001$ & $<0.001$ & 0.044 & 0.494 \\
\hline \multicolumn{5}{|c|}{ Sodium (mmol/L) } \\
\hline Group 1 & $2.9 \pm 3.7$ & $6.2 \pm 3.6$ & $9.4 \pm 6.1$ & $1.5 \pm 4.6$ \\
\hline Group 2 & $10.3 \pm 9.8$ & $13.4 \pm 10.7$ & $6.0 \pm 4.2$ & $1.2 \pm 1.8$ \\
\hline$p$-Value & 0.002 & $<0.001$ & 0.013 & 0.656 \\
\hline \multicolumn{5}{|c|}{ BUN (mg/dL) } \\
\hline Group 1 & $0.3 \pm 1.7$ & $0.4 \pm 1.4$ & $0.3 \pm 1.2$ & $0.6 \pm 1.7$ \\
\hline Group 2 & $2.1 \pm 0.9$ & $3.8 \pm 1.0$ & $1.6 \pm 1.2$ & $0.3 \pm 1.2$ \\
\hline$p$-Value & $<0.001$ & $<0.001$ & 0.003 & 0.827 \\
\hline \multicolumn{5}{|c|}{ Lactic acid (mmol/L) } \\
\hline Group 1 & $0.1 \pm 0.3$ & $0.6 \pm 0.5$ & $1.1 \pm 0.6$ & $0.5 \pm 0.7$ \\
\hline Group 2 & $0.7 \pm 0.3$ & $1.5 \pm 0.5$ & $1.5 \pm 0.5$ & $1.5 \pm 0.4$ \\
\hline$p$-Value & $<0.001$ & $<0.001$ & 0.04 & 0.351 \\
\hline \multicolumn{5}{|c|}{ Phosphate (mg/dL) } \\
\hline Group 1 & $-0.1 \pm 0.2$ & $-0.1 \pm 0.1$ & $-0.2 \pm 0.3$ & $0.04 \pm 0.5$ \\
\hline Group 2 & $0.1 \pm 0.1$ & $0.3 \pm 0.2$ & $0.4 \pm 0.3$ & $0.3 \pm 0.2$ \\
\hline$p$-Value & 0.001 & $<0.001$ & $<0.001$ & 0.026 \\
\hline \multicolumn{5}{|c|}{ Uric acid (mg/dL) } \\
\hline Group 1 & $0.1 \pm 0.1$ & $0.2 \pm 0.3$ & $0.3 \pm 0.3$ & $0.3 \pm 0.3$ \\
\hline Group 2 & $0.1 \pm 0.2$ & $0.3 \pm 0.9$ & $0.4 \pm 0.3$ & $0.2 \pm 0.3$ \\
\hline$p$-Value & 0.931 & 0.308 & 0.411 & 0.675 \\
\hline
\end{tabular}




\subsection{Effect of on Serum Copeptin, Sodium, BUN, and Osmolarity}

Serum copeptin, sodium, BUN, and osmolarity significantly increased after ingestion of apple juice, and all patterns demonstrated a greater and sharper increase in group 2 compared to group 1. Copeptin concentration achieved its peak after $30 \mathrm{~min}$ in both groups and remained markedly higher after fast ingestion compared to slow ingestion (Figure 3A). The change in copeptin concentrations compared with baseline was significantly greater in group 2 after $15 \mathrm{~min}$ and $30 \mathrm{~min}(p=0.005$ and $p=0.001$, respectively), but did not remain significant after $60 \mathrm{~min}$ and $120 \mathrm{~min}$ (Table 3). Serum sodium, BUN, and osmolarities showed very similar trends with time. In both groups, serum sodium, BUN, and osmolarity started to increase after $15 \mathrm{~min}$ (Figure 3B-D). While the changes were statistically significant in both groups, the serum sodium, BUN, and osmolarity levels in group 2 demonstrated dramatic upsurges compared to the modest increases in group 1. Group 2 showed greater increases serum sodium, BUN, and osmolarity after $15 \mathrm{~min}(0.002$, $<0.001$, and 0.001 , respectively), $30 \mathrm{~min}(<0.001$ for all), and $60 \mathrm{~min}(0.01,0.003$, and 0.04 , respectively) (Table 3).
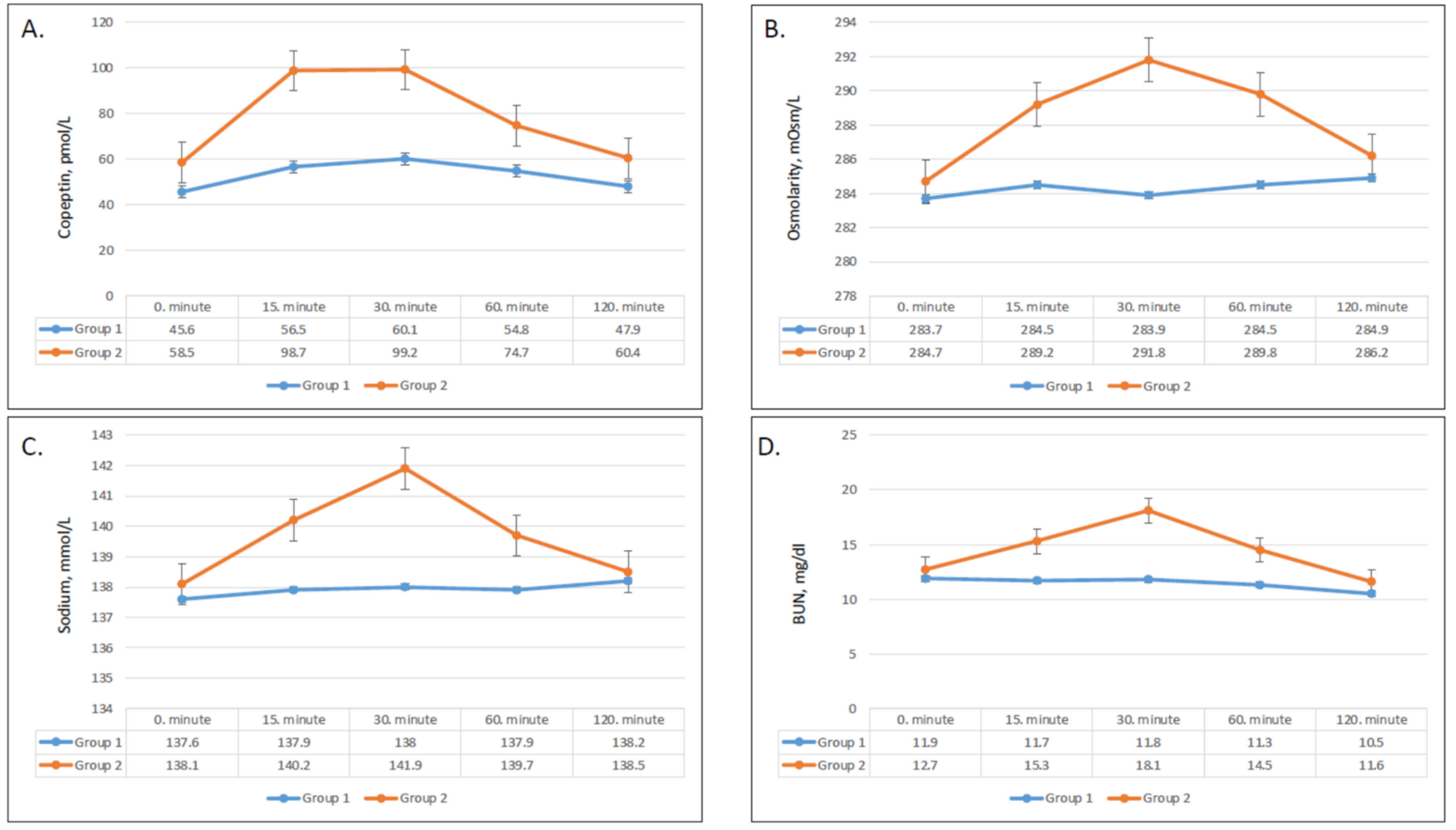

Figure 3. Changes in plasma copeptin (A), plasma osmolarity (B), sodium (C), and BUN (blood urea nitrogen) (D) values in group 1 and group 2.

\subsection{Effect on Plasma Lactic Acid, Uric Acid, and Phosphate}

Lactic acid levels had a steep rise starting after $15 \mathrm{~min}$ and increased from 1 to $2.6 \mathrm{mmol} / \mathrm{L}$ after $30 \mathrm{~min}$ in group 2 (Figure $4 \mathrm{~A}$ ). On the other hand, only a slight increase from 0.9 to $1.5 \mathrm{mmol} / \mathrm{L}$ was seen after $30 \mathrm{~min}$ in group 1 . The differences in changes of serum lactic acid compared to baseline were significant after $15 \mathrm{~min}, 30 \mathrm{~min}$, and $60 \mathrm{~min}$ ( $p=0.001,0.001$, and 0.04, respectively) (Table 3).

After ingestion of apple juice, serum phosphate levels slightly increased in group 2 but did not show a significant change in group 1 (Figure 4B). Compared with baseline, the mean phosphate concentrations were significantly higher in group 2 at all times (Figure 4B), while phosphate levels changed minimally in group 1 (Table 3 ). 

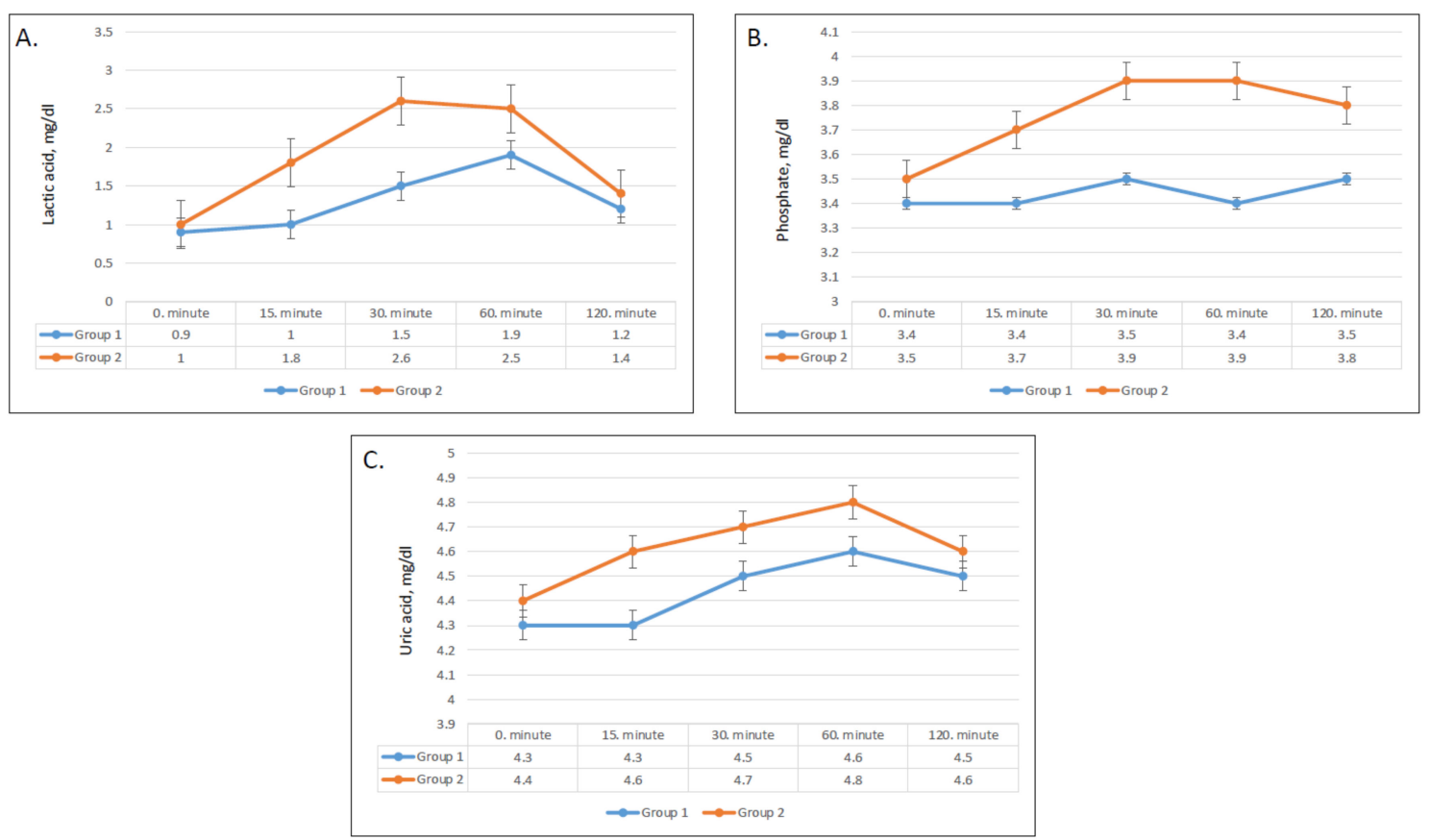

Figure 4. Changes in plasma lactic acid (A), plasma uric acid (B), and phosphate (C) values in group 1 and group 2.

Serum uric acid levels showed a significant difference in pattern between the two groups $(p<0.01)$, whereas the changes in uric acid levels over time were not statistically significant $(p=0.4)$ (Table 2). Although serum uric acid levels in group 2 were higher at all times (Figure 4C), the differences compared with baseline were not significant (Table 3).

\section{Discussion}

Here, we investigated whether the speed of consumption of apple juice would change key modulators of glucose/lipid metabolism and markers of cardiorenal morbidity. Following prior studies suggesting that fructose causes its metabolic effects by decreasing ATP levels in the liver, we hypothesized that the administration of fructose over a shorter time would have greater metabolic effects than giving the same amount over a longer time. Consistent with our hypothesis, we showed significantly greater changes in serum glucose, insulin, HOMA-IR score, FGF-21, osmolarity, copeptin, sodium, BUN, and lactic acid levels with fast intake of apple juice compared to slow intake.

Our primary finding was that the metabolic effects of fructose were much more prominent with fast ingestion of the apple juice. According to the results of a recent study in mice, when fructose is ingested in low amounts, the majority of fructose metabolism occurs in the intestines and only a small remaining portion reaches the liver. However, high amounts of fructose overwhelm intestinal absorption capacity, allowing the liver to have a greater role in its metabolism into glucose, lactate, and glycerate. Either way, fructose metabolism into glucose, lactate, and fatty acids [2] leads to an increase in blood glucose and lactate levels. Our results showed that fast ingestion of $100 \%$ apple juice caused a significantly steeper and higher increase in both serum glucose and lactate levels, confirming that fast ingestion of fruit juice causes rapid absorption and metabolization of fructose. It is also plausible that faster ingestion of 100\% juice with its high fructose load may saturate intestinal metabolism and cause more fructose-induced liver injury, although the present findings are insufficient to demonstrate this definitively.

One key finding of the present study was that fast ingestion of 100\% apple juice resulted in significantly higher FGF-21 levels. FGF-21 is a metabolic hormone synthesized largely by the liver, and fructose is known to be a robust stimulus for FGF-21 release into circulation [27]. It was previously shown that acute ingestion of an oral fructose load results in an acute rise in serum FGF21 levels and a return to baseline within $5 \mathrm{~h}$ [28]. In addition 
to corroborating the previous findings, our results imply that faster ingestion of a fructose content leads to a stronger FGF-21 response. It is thought that FGF-21 may have a protective role in energy metabolism by acting as an insulin sensitizer [29] and by stimulating the oxidation of fatty acids and inhibition of lipogenesis [30]. Furthermore, FGF-21 was shown to protect against fructose-induced liver inflammation in mice [31]. Nevertheless, elevated circulating FGF-21 levels have been associated with poor metabolic health in humans and shown to correlate positively with fasting glucose [32], fasting insulin, and triglycerides and negatively with high-density lipoprotein cholesterol (HDL) [33]. Importantly, high serum FGF-21 is a predictor of obesity, insulin resistance, and metabolic syndrome [33,34]. Although the role of FGF-21 in the context of increased fructose consumption is yet to be uncovered, the increase in FGF-21 after fast juice consumption can be hypothetically explained by a defense mechanism which counterbalances the increased glucose and insulin levels.

Another finding of our study was significantly higher serum osmolarity in response to fast juice consumption. One simple explanation is that this was due to the osmolarity of the fructose that was absorbed. However, we noted an increase in serum sodium that would not be expected if this were the only mechanism. We previously reported that laboratory rats administered chronically fructose solutions also develop high plasma and urine osmolarity in association with a rise in serum copeptin levels [35-37]. In these earlier studies, it was shown that the rise in serum vasopressin was not dependent on the osmolarity of the fructose but rather mediated by fructose metabolism $[22,24,38]$. The mechanism appears to result from a shift of water into the cell, likely from the rapid synthesis of glycogen that carries water [35]. Intracellular fluid shift results in relative hyperosmolarity of plasma. Possibly by inducing faster glycogen synthesis, fast consumption of $100 \%$ apple juice may lead to a greater water shift with higher osmolarity as depicted by our results. It can also be hypothesized that ingestion of high amounts of sweetened beverages may cause transitory dehydration. Beverages high in carbohydrate content are also hypertonic and greatly increase the secretion of fluid into the gut, which slows fluid absorption and uptake into the body [39]. The rise in the osmolarity, in return, directly stimulates copeptin secretion, which is depicted by the elevated copeptin levels. In addition, fructose is known to stimulate the production of vasopressin in the hypothalamus [22]. The stimulation of the $\mathrm{V} 1 \mathrm{~b}$ receptor by vasopressin has been found to be responsible for many of the metabolic features mediated by fructose in mice. While the mechanism could involve stimulation of ACTH or glucagon, in the reported study, the primary finding was that V1b receptor amplified fructokinase expression, an effect that can enhance the production of fat and other features of the metabolic syndrome. We postulated that this may represent another function of vasopressin to protect against dehydration, as fat can act as a source of metabolic water (due to the ability of fat to release water upon its oxidation) [24].

Our results further depicted a striking increase in serum BUN levels after rapid juice ingestion. Previous studies have proposed that fructose-rich diet is a risk factor for the development and progression of CKD due to enhanced glomerulosclerosis and tubulointerstitial inflammation [40]. Fructose is predominantly transported by GLUT5 and GLUT2 in the proximal tubule, where it is phosphorylated by fructokinase (ketohexokinase), which causes ATP consumption and uric acid generation through xanthine oxidoreductase [40]. Therefore, fructose is an acute source of oxidative stress and uric acid production in the kidneys [41]. In rat models, fructose-containing sweetened beverages were found to markedly aggravate the renal impairment induced by mild heat dehydration [36]. Acute effects of fructose load on renal clearance are yet to be elucidated. Nevertheless, the acute and temporary increase in BUN parallels the increase in serum sodium. This finding points to fluid shift as the main mechanism of the present changes in serum BUN.

In our study, serum osmolarity rose, most likely as a result of the temporary hypernatremia induced by intracellular water shift, increased BUN, and, to a lesser extent, the higher plasma glucose levels observed with rapid apple juice ingestion. Although the change in osmolarity was short-lived and not clinically significant in the present study, it 
should be noted that hyperosmolarity was shown to be associated with increased mortality in patients with acute coronary syndrome [42,43], acute kidney injury [44], and hypertension $[45,46]$. Previous studies have also shown an association between hyperosmolarity and obesity [47]. Elevations in copeptin (a stable biomarker of vasopressin) predict the development of metabolic syndrome and are present in most subjects with this condition $[48,49]$. Our results showed dramatically and significantly higher concentrations of copeptin with fast consumption of $100 \%$ juice in the first $30 \mathrm{~min}$. As discussed earlier, the rise in vasopressin levels is now known to be a direct mediator of fructose-induced metabolic syndrome, consistent with the hypothesis that rapid ingestion carries greater metabolic consequences.

Our findings also suggest that $100 \%$ apple juice significantly increases plasma phosphate levels. During intrahepatic fructose metabolism, fructose phosphorylation depletes the intracellular phosphate, which results in conversion of adenosine triphosphate (ATP) to adenosine monophosphate (AMP), which is later catabolized into uric acid [50]. Indeed, previous studies found decreased plasma inorganic phosphate levels in response to fructose [51]. It is highly likely that the elevated levels of serum inorganic phosphate after apple juice ingestion were related to the phosphorus content of apple juice itself rather than to fructose metabolism, as apple juice is known to be a rich source of phosphorus, containing $7 \mathrm{mg}$ of phosphorus per $100 \mathrm{~mL}$ [52].

Lastly, we observed increases in uric acid; however, differences between uric acid concentrations between fast and slow ingestion were not statistically significant. Fructose is the only sugar that increases purine degradation and production of uric acid [53]. Importantly, hyperuricemia has a major causal role in fructose induced metabolic syndrome [54], likely due to inhibition of insulin-mediated endothelial nitric oxide synthesis [55,56]. Given that uric acid mediates many hazardous effects of fructose, limiting the rise in uric acid after the ingestion of fructose may have clinical benefits in the long term. Our findings showed a consistent trend toward higher uric acid levels with fast ingestion, while the association was found statistically insignificant. However, the present study may be underpowered to detect small differences.

This study had some limitations. First, the sample size was small, which limited the ability to detect slight differences. Secondly, we assumed that the observed changes were mainly the response to the fructose content of $100 \%$ apple juice. By preferring apple juice over citrus juice, which has minimal known antioxidant activity, we tried to limit such a confounding impact. Nevertheless, we used 100\% apple juice instead of a fructosecontaining solution to mimic the "real-life" consumption of a common beverage. Other ingredients of apple juice may have directly or indirectly affected the biomarkers evaluated. It is known that copeptin level is higher in males compared to females; thus, the additional male subject in group 2 may explain the slightly higher copeptin level at baseline. However, the relative increase in copeptin in group 2 compared to group 1 suggests that the responses to the apple juice based on speed of ingestion were significant. Moreover, we did not control the water intake during the $8 \mathrm{~h}$ period of fasting before the experiments, and differences in water intake between groups could have impacted the copeptin levels, especially if consumed immediately before the commencement of the experimental protocol. It should also be noted that current findings are insufficient to conclude any long-term consequences of fast versus slow fructose ingestion, and future research is needed to elucidate whether such an association exists.

In conclusion, rapid consumption of $100 \%$ apple juice causes a more dramatic metabolic response, characterized by increases in serum glucose, insulin, FGF-21, copeptin, sodium, BUN, osmolarity, and lactic acid. The study suggests that the metabolic effects of fructose are not just driven by the amount ingested, but by how rapidly it is ingested. Sugary beverages may be distinct from solid foods in being able to induce more severe metabolic effects due to the frequently rapid speed of ingestion. In clinical practice, advocating the consumption of sweetened beverages and fruit juices in spaced-out smaller portions may alleviate the harmful effects of fructose. 
Author Contributions: Contributed substantially to the conceptualization or design of the work or the acquisition, analysis, or interpretation of data for the work, L.A.E., B.G., S.I., T.D., A.B., R.J.J., M.A.L. and M.K.; drafted the work or revised it critically for important intellectual content, L.A.E., B.A., T.D., A.C., A.A.-H., L.G.S.-L., M.A.L., R.J.J. and M.K.; approved the final version to be published, M.K., B.G., L.A.E., T.D., B.A., S.I., A.C., A.A.-H., L.G.S.-L., M.A.L. and R.J.J. All authors read and agreed to the published version of the manuscript.

Funding: This study was not funded by any grant. R.J.J. and M.A.L. were partially funded by NIH DK121496.

Institutional Review Board Statement: The Koc University School of Medicine ethics committee approved the study protocol (2020.275.IRB1.098).

Informed Consent Statement: Written informed consent was obtained from all participants before enrollment.

Data Availability Statement: Data described in the manuscript will be made available upon request pending approval and payment if necessary.

Acknowledgments: M.K. gratefully acknowledges use of the services and facilities of the Koc University Research Center for Translational Medicine (KUTTAM), funded by the Presidency of Turkey, Presidency of Strategy and Budget. The content is solely the responsibility of the authors and does not necessarily represent the official views of the Presidency of Strategy and Budget.

Conflicts of Interest: L.G.S.-L., M.A.L., and R.J.J. have equity with Colorado Research Partners, LLC, which is developing inhibitors of fructose metabolism; R.J.J. also has equity with XORTX therapeutics. R.J.J. has consulted for Horizon Pharma. All other authors disclose no conflicts of interest.

\section{References}

1. Herrick, K.A.; Terry, A.L.; Afful, J. Beverage Consumption among Youth in the United States, 2013-2016; NCHS Data Brief, no 320; National Center for Health Statistics: Hyattsville, MD, USA, 2018.

2. Malik, V.S.; Hu, F.B. Sugar-sweetened beverages and cardiometabolic health: An update of the evidence. Nutrients 2019, 11, 1840. [CrossRef]

3. Yerlikaya, A.; Dagel, T.; King, C.; Kuwabara, M.; Lanaspa, M.A.; Andres-Hernando, A.; Covic, A.; Manitius, J.; Sag, A.A.; Kanbay, M. Dietary and commercialized fructose: Sweet or sour? Int. Urol. Nephrol. 2017, 49, 1611-1620. [CrossRef]

4. Mullee, A.; Romaguera, D.; Pearson-Stuttard, J.; Viallon, V.; Stepien, M.; Freisling, H.; Fagherazzi, G.; Mancini, F.R.; BoutronRuault, M.C.; Kühn, T.; et al. Association between soft drink consumption and mortality in 10 European countries. JAMA Intern. Med. 2019, 179, 1479-1490. [CrossRef]

5. Walker, R.W.; Dumke, K.A.; Goran, M.I. Fructose content in popular beverages made with and without high-fructose corn syrup. Nutrition 2014, 30, 928-935. [CrossRef] [PubMed]

6. Stanhope, K.L.; Schwarz, J.M.; Keim, N.L.; Griffen, S.C.; Bremer, A.A.; Graham, J.L.; Hatcher, B.; Cox, C.L.; Dyachenko, A.; Zhang, W.; et al. Consuming fructose-sweetened, not glucose-sweetened, beverages increases visceral adiposity and lipids and decreases insulin sensitivity in overweight/obese humans. J. Clin. Investig. 2009, 119, 1322-1334. [CrossRef]

7. Jang, C.; Hui, S.; Lu, W.; Cowan, A.J.; Morscher, R.J.; Lee, G.; Liu, W.; Tesz, G.J.; Birnbaum, M.J.; Rabinowitz, J.D. The small intestine converts dietary fructose into glucose and organic acids. Cell Metab. 2018, 27, 351-361. [CrossRef] [PubMed]

8. Lanaspa, M.A.; Sanchez-Lozada, L.G.; Choi, Y.J.; Cicerchi, C.; Kanbay, M.; Roncal-Jimenez, C.A.; Ishimoto, T.; Li, N.; Marek, G.; Duranay, M.; et al. Uric acid induces hepatic steatosis by generation of mitochondrial oxidative stress: Potential role in fructose-dependent and -independent fatty liver. J. Biol. Chem. 2012, 287, 40732-40744. [CrossRef] [PubMed]

9. Tappy, L.; Le, K.A. Metabolic effects of fructose and the worldwide increase in obesity. Physiol. Rev. 2010, 90, 23-46. [CrossRef]

10. Kanbay, M.; Bulbul, M.C.; Copur, S.; Afsar, B.; Sag, A.A.; Siriopol, D.; Kuwabara, M.; Badarau, S.; Covic, A.; Ortiz, A. Therapeutic implications of shared mechanisms in non-alcoholic fatty liver disease and chronic kidney disease. J. Nephrol. 2020. [CrossRef] [PubMed]

11. Hannou, S.A.; Haslam, D.E.; McKeown, N.M.; Herman, M.A. Fructose metabolism and metabolic disease. J. Clin. Investig. 2018, 128, 545-555. [CrossRef]

12. Sánchez-Lozada, L.G.; Tapia, E.; Jiménez, A.; Bautista, P.; Cristóbal, M.; Nepomuceno, T.; Soto, V.; Ávila-Casado, C.; Nakagawa, T.; Johnson, R.J.; et al. Fructose-induced metabolic syndrome is associated with glomerular hypertension and renal microvascular damage in rats. Am. J. Physiol. Renal Physiol. 2007, 292, F423-F429. [CrossRef]

13. Abdulla, M.H.; Sattar, M.A.; Johns, E.J. The relation between fructose-induced metabolic syndrome and altered renal haemodynamic and excretory function in the rat. Int. J. Nephrol. 2011, 2011, 934659. [CrossRef] [PubMed]

14. Lanaspa, M.A.; Andres-Hernando, A.; Orlicky, D.J.; Cicerchi, C.; Jang, C.; Li, N.; Milagres, T.; Kuwabara, M.; Wempe, M.F.; Rabinowitz, J.D.; et al. Ketohexokinase C blockade ameliorates fructose-induced metabolic dysfunction in fructose-sensitive mice. J. Clin. Investig. 2018, 128, 2226-2238. [CrossRef] 
15. Lanaspa, M.A.; Epperson, L.E.; Li, N.; Cicerchi, C.; Garcia, G.E.; Roncal-Jimenez, C.A.; Trostel, J.; Jain, S.; Mant, C.T.; Rivard, C.J.; et al. Opposing activity changes in AMP deaminase and AMP-activated protein kinase in the hibernating ground squirrel. PLoS ONE 2015, 10, e0123509. [CrossRef]

16. Andres-Hernando, A.; Orlicky, D.J.; Kuwabara, M.; Ishimoto, T.; Nakagawa, T.; Johnson, R.J.; Lanaspa, M.A. Deletion of fructokinase in the liver or in the intestine reveals differential effects on sugar-induced metabolic dysfunction. Cell Metab. 2020, 32, 117-127. [CrossRef]

17. Togo, J.; Hu, S.; Li, M.; Niu, C.; Speakman, J.R. Impact of dietary sucrose on adiposity and glucose homeostasis in C57BL/6J mice depends on mode of ingestion: Liquid or solid. Mol. Metab. 2019, 27, 22-32. [CrossRef]

18. Sundborn, G.; Thornley, S.; Merriman, T.R.; Lang, B.; King, C.; Lanaspa, M.A.; Johnson, R.J. Are liquid sugars different from solid sugar in their ability to cause metabolic syndrome? Obesity 2019, 27, 879-887. [CrossRef]

19. Enhörning, S.; Hedblad, B.; Nilsson, P.M.; Engström, G.; Melander, O. Copeptin is an independent predictor of diabetic heart disease and death. Am. Heart J. 2015, 169, 549-556.e1. [CrossRef]

20. Zhu, F.X.; Wu, H.L.; Tu, K.S.; Chen, J.X.; Zhang, M.; Shi, C. Serum levels of copeptin are associated with type 2 diabetes and diabetic complications in Chinese population. J. Diabetes Complicat. 2016, 30, 1566-1570. [CrossRef]

21. Morgenthaler, N.G. Copeptin: A biomarker of cardiovascular and renal function. Congest. Heart Fail. 2010, 16 (Suppl. 1), S37-S44. [CrossRef]

22. Song, Z.; Roncal-Jimenez, C.A.; Lanaspa-Garcia, M.A.; Oppelt, S.A.; Kuwabara, M.; Jensen, T.; Milagres, T.; Andres-Hernando, A.; Ishimoto, T.; Garcia, G.E.; et al. Role of fructose and fructokinase in acute dehydration-induced vasopressin gene expression and secretion in mice. J. Neurophysiol. 2017, 117, 646-654. [CrossRef]

23. Chapman, C.L.; Johnson, B.D.; Sackett, J.R.; Parker, M.D.; Schlader, Z.J. Soft drink consumption during and following exercise in the heat elevates biomarkers of acute kidney injury. Am. J. Physiol. Regul. Integr. Comp. Physiol. 2019, 316, 189-198. [CrossRef] [PubMed]

24. Andres-Hernando, A.; Jensen, T.J.; Kuwabara, M.; Orlicky, D.J.; Cicerchi, C.; Li, N.; Roncal-Jimenez, C.A.; Garcia, G.E.; Ishimoto, T.; Maclean, P.S.; et al. Vasopressin mediates Fructose-induced Metabolic Syndrome by activating the V1b Receptor. JCI Insight 2021, 6, e140848. [CrossRef]

25. Kim, M.; Doridot, L.; Cunniff, J.C.; Parker, T.S.; Levine, D.M.; Hellerstein, M.K.; Hudgins, L.C.; Maratos-Flier, E.; Herman, M.A. A critical role for ChREBP-mediated FGF21 secretion in hepatic fructose metabolism. Mol. Metab. 2017, 6, 14-21.

26. Matthews, D.R.; Hosker, J.P.; Rudenski, A.S.; Naylor, B.A.; Treacher, D.F.; Turner, R.C. Homeostasis model assessment: Insulin resistance and beta-cell function from fasting plasma glucose and insulin concentrations in man. Diabetologia 1985, 28, 412-419. [CrossRef]

27. Samms, R.J.; Lewis, J.E.; Norton, L.; Stephens, F.B.; Gaffney, C.J.; Butterfield, T.; Smith, D.P.; Cheng, C.C.; Perfield, J.W.; Adams, A.C.; et al. FGF21 Is an Insulin-Dependent Postprandial Hormone in Adult Humans. J. Clin. Endocrinol. Metab. 2017, 102, 3806-3813. [CrossRef]

28. Dushay, J.R.; Toschi, E.; Mitten, E.K.; Fisher, F.M.; Herman, M.A.; Maratos-Flier, E. Fructose ingestion acutely stimulates circulating FGF21 levels in humans. Mol. Metab. 2015, 4, 51-57. [CrossRef]

29. Markan, K.R.; Naber, M.C.; Ameka, M.K.; Anderegg, M.D.; Mangelsdorf, D.J.; Kliewer, S.A.; Potthoff, M.J. Circulating FGF21 is liver derived and enhances glucose uptake during refeeding and overfeeding. Diabetes 2014, 63, 4057-4063. [CrossRef] [PubMed]

30. Fisher, F.M.; Maratos-Flier, E. Understanding the Physiology of FGF21. Annu. Rev. Physiol. 2016, 78, 223-241. [CrossRef]

31. Zhao, C.; Liu, L.; Liu, Q.; Li, F.; Zhang, L.; Zhu, F.; Shao, T.; Barve, S.; Chen, Y.; Li, X.; et al. Fibroblast growth factor 21 is required for the therapeutic effects of Lactobacillus rhamnosus GG against fructose-induced fatty liver in mice. Mol. Metab. 2019, 29, 145-157. [CrossRef]

32. Chavez, A.O.; Molina-Carrion, M.; Abdul-Ghani, M.A.; Folli, F.; Defronzo, R.A.; Tripathy, D. Circulating fibroblast growth factor-21 is elevated in impaired glucose tolerance and type 2 diabetes and correlates with muscle and hepatic insulin resistance. Diabetes Care 2009, 32, 1542-1546. [CrossRef]

33. Zhang, X.; Yeung, D.C.; Karpisek, M.; Stejskal, D.; Zhou, Z.G.; Liu, F.; Wong, R.L.; Chow, W.S.; Tso, A.W.; Lam, K.S.; et al. Serum fgf21 levels are increased in obesity and are independently associated with the metabolic syndrome in humans. Diabetes 2008, 57, 1246-1253. [CrossRef]

34. Dushay, J.; Chui, P.C.; Gopalakrishnan, G.S.; Varela-Rey, M.; Crawley, M.; Fisher, F.M.; Badman, M.K.; Martinez-Chantar, M.L.; Maratos-Flier, E. Increased fibroblast growth factor 21 in obesity and nonalcoholic fatty liver disease. Gastroenterology 2010, 139, 456-463. [CrossRef]

35. Johnson, R.J.; Stenvinkel, P.; Andrews, P.; Sánchez-Lozada, L.G.; Nakagawa, T.; Gaucher, E.; Andres-Hernando, A.; RodriguezIturbe, B.; Jimenez, C.R.; Garcia, G.; et al. Fructose metabolism as a common evolutionary pathway of survival associated with climate change, food shortage and droughts. J. Intern. Med. 2020, 287, 252-262. [CrossRef]

36. García-Arroyo, F.E.; Cristóbal, M.; Arellano-Buendía, A.S.; Osorio, H.; Tapia, E.; Soto, V.; Madero, M.; Lanaspa, M.A.; RoncalJiménez, C.; Bankir, L.; et al. Rehydration with soft drink-like beverages exacerbates dehydration and worsens dehydrationassociated renal injury. Am. J. Physiol. Regul. Integr. Comp. Physiol. 2016, 311, 57-65. [CrossRef]

37. García-Arroyo, F.E.; Tapia, E.; Blas-Marron, M.G.; Gonzaga, G.; Silverio, O.; Cristóbal, M.; Osorio, H.; Arellano-Buendía, A.S.; Zazueta, C.; Aparicio-Trejo, O.E.; et al. Vasopressin mediates the renal damage induced by limited fructose rehydration in recurrently dehydrated rats. Int. J. Biol. Sci. 2017, 13, 961-975. [CrossRef] 
38. Wolf, J.P.; Nguyen, N.U.; Dumoulin, G.; Berthelay, S. Influence of hypertonic monosaccharide infusions on the release of plasma arginine vasopressin in normal humans. Horm. Metab. Res. 1992, 24, 379-383. [CrossRef] [PubMed]

39. Afsar, B.; Turkmen, K.; Covic, A.; Kanbay, M. An update on coronary artery disease and chronic kidney disease. Int. J. Nephrol. 2014, 2014, 767424. [CrossRef] [PubMed]

40. Cirillo, P.; Gersch, M.S.; Mu, W.; Scherer, P.M.; Kim, K.M.; Gesualdo, L.; Henderson, G.N.; Johnson, R.J.; Sautin, Y.Y. Ketohexokinase-dependent metabolism of fructose induces proinflammatory mediators in proximal tubular cells. J. Am. Soc. Nephrol. 2009, 20, 545-553. [CrossRef] [PubMed]

41. Johnson, R.J.; Sanchez-Lozada, L.G.; Nakagawa, T. The Effect of Fructose on Renal Biology and Disease. J. Am. Soc. Nephrol. 2010, 21, 2036-2039. [CrossRef]

42. Capes, S.E.; Hunt, D.; Malmberg, K.; Gerstein, H.C. Stress hyperglycaemia and increased risk of death after myocardial infarction in patients with and without diabetes: A systematic overview. Lancet 2000, 355, 773-778. [CrossRef]

43. Kanbay, M.; Yilmaz, S.; Dincer, N.; Ortiz, A.; Sag, A.A.; Covic, A.; Sánchez-Lozada, L.G.; Lanaspa, M.A.; Cherney, D.Z.; Johnson, R.J.; et al. Antidiuretic hormone and serum osmolarity physiology and related outcomes: What is old, what is new, and what is unknown? J. Clin. Endocrinol. Metab. 2019, 104, 5406-5420. [CrossRef]

44. Kanbay, M.; Siriopol, D.; Ozdogan, E.; Afsar, B.; Ertuglu, L.A.; Grigore, M.; Sag, A.A.; Kuwabara, M.; Lanaspa, M.A.; Ortiz, A.; et al. Serum osmolarity as a potential predictor for contrast-induced nephropathy following elective coronary angiography. Int. Urol. Nephrol. 2020, 52, 541-547. [CrossRef]

45. Kuwabara, M.; Kanbay, M.; Niwa, K.; Ae, R.; Andres-Hernando, A.; Roncal-Jimenez, C.A.; Garcia, G.; Sánchez-Lozada, L.G.; Rodriguez-Iturbe, B.; Hisatome, I.; et al. Hyperosmolarity and increased serum sodium concentration are risks for developing hypertension regardless of salt intake: A five-year cohort study in Japan. Nutrients 2020, 12, 1422. [CrossRef] [PubMed]

46. Kanbay, M.; Aslan, G.; Afsar, B.; Dagel, T.; Siriopol, D.; Kuwabara, M.; Incir, S.; Camkiran, V.; Rodriguez-Iturbe, B.; Lanaspa, M.A.; et al. Acute effects of salt on blood pressure are mediated by serum osmolality. J. Clin. Hypertens. 2018, 20, 1447-1454. [CrossRef] [PubMed]

47. Stookey, J.D.; Kavouras, S.; Suh, H.; Lang, F. Underhydration is associated with obesity, Chronic Diseases, and Death within 3 to 6 Years in the U.S. Population Aged 51-70 Years. Nutrients 2020, 12, 905. [CrossRef] [PubMed]

48. Enhörning, S.; Bankir, L.; Bouby, N.; Struck, J.; Hedblad, B.; Persson, M.; Morgenthaler, N.G.; Nilsson, P.M.; Melander, O. Copeptin, a marker of vasopressin, in abdominal obesity, diabetes and microalbuminuria: The prospective Malmo Diet and Cancer Study cardiovascular cohort. Int. J. Obes. 2013, 37, 598-603. [CrossRef]

49. Enhorning, S.; Struck, J.; Wirfalt, E.; Hedblad, B.; Morgenthaler, N.G.; Melander, O. Plasma copeptin, a unifying factor behind the metabolic syndrome. J. Clin. Endocrinol. Metab. 2011, 96, 1065-1072. [CrossRef]

50. De Oliveira, E.P.; Burini, R.C. High plasma uric acid concentration: Causes and consequences. Diabetol. Metab. Syndr. 2012, 4, 1-7. [CrossRef]

51. Hallfrisch, J.; Ellwood, K.; Michaelis OEt Reiser, S.; Prather, E.S. Plasma fructose, uric acid, and inorganic phosphorus responses of hyperinsulinemic men fed fructose. J. Am. Coll. Nutr. 1986, 5, 61-68. [CrossRef]

52. Faroqui, M.; Mirza, S.K.; Aarwal, B.R.; Faroqui, M. Physical and nutritional analysis of apple juice samples. Anal. Chem. 2009, 8, 26-28.

53. Abdelmalek, M.F.; Lazo, M.; Horska, A.; Bonekamp, S.; Lipkin, E.W.; Balasubramanyam, A.; Bantle, J.P.; Johnson, R.J.; Diehl, A.M.; Clark, J.M.; et al. Higher dietary fructose is associated with impaired hepatic adenosine triphosphate homeostasis in obese individuals with type 2 diabetes. Hepatology 2012, 56, 952-960. [CrossRef] [PubMed]

54. Nakagawa, T.; Hu, H.; Zharikov, S.; Tuttle, K.R.; Short, R.A.; Glushakova, O.; Ouyang, X.; Feig, D.I.; Block, E.R.; Herrera-Acosta, J.; et al. A causal role for uric acid in fructose-induced metabolic syndrome. Am. J. Physiol. Renal Physiol. 2006, 290, 625-631. [CrossRef] [PubMed]

55. Johnson, R.J.; Perez-Pozo, S.E.; Sautin, Y.Y.; Manitius, J.; Sanchez-Lozada, L.G.; Feig, D.I.; Shafiu, M.; Segal, M.; Glassock, R.J.; Shimada, M.; et al. Hypothesis: Could excessive fructose intake and uric acid cause type 2 diabetes? Endocr. Rev. 2009, 30, 96-116. [CrossRef]

56. Kanbay, M.; Solak, Y.; Dogan, E.; Lanaspa, M.A.; Covic, A. Uric acid in hypertension and renal disease: The chicken or the egg? Blood Purif. 2010, 30, 288-295. [CrossRef] 